\title{
Two contrasting outcomes of weight loss surgery: Positive impact on the heart, negative impact on the liver
}

\author{
Mohamed F. Algahim, Thomas R. Lux, J oshua G. Leichman, Heinrich Taegtmeyer \\ The University of Texas Medical School at Houston, Houston, Texas, United States \\ Correspondence: Heinrich Taegtmeyer. Address: Department of Internal Medicine, Division of Cardiology, University of \\ Texas Houston Medical School, 6431 Fannin, MSB 1.246 Houston, TX 77030, Texas, United States. \\ Email: Heinrich.Taegtmeyer@uth.tmc.edu
}

Received: October 21,2014

Accepted: December 21, 2014 Online Published: January 1, 2015

DOI : $10.5430 /$ crim.v2n2p1

URL: http://dx.doi.org/10.5430/crim.v2n2p1

\begin{abstract}
Bariatric surgery results in significant weight loss in severely obese patients and is associated with beneficial as well as unintended negative consequences. Here we highlight the divergent impact of rapid weight loss in two individuals who underwent bariatric surgery. The first patient is a 58-year-old severely obese [body mass index (BMI) of $48.8 \mathrm{~kg} / \mathrm{m}^{2}$ ] Caucasian woman with metabolic syndrome and impaired left ventricular systolic function [preoperative left ventricular ejection fraction (LVEF) 29\%]. After undergoing gastric banding, the LVEF improved to 65\% at 24 months. This, along with a marked reversal of obesity-related comorbidities following surgery highlight the beneficial impacts that have popularized bariatric surgery. The second patient is a 27-year-old extremely obese (BMI $=81.0 \mathrm{~kg} / \mathrm{m}^{2}$ ) Hispanic man without metabolic syndrome and with normal preoperative cardiac and end organ function. One year after undergoing Roux-en-Y gastric bypass, his BMI had decreased to $28 \mathrm{~kg} / \mathrm{m}^{2}$. The initial weight loss was rapid and paralleled by a loss of lean mass, muscle wasting and the development of cachexia with progressive liver failure and a diagnosis of crytopgenic hepatic cirrhosis.
\end{abstract}

Herein we discuss the cases in detail and provide insight into the divergent impact of rapid weight loss on metabolic homeostasis, the heart, and end organ function. We hope this will aid with the preoperative risk/benefit assessment of severely obese patients being considered for weight loss surgery.

\section{Keywords}

Weight loss, Bariatric surgery, Obesity

\section{I ntroduction}

Bariatric surgery results in significant weight loss in severely obese patients. The two most common surgical techniques are Roux-en-Y and gastric banding; the benefits of this method on weight loss and cardiometabolic health and longevity are well documented ${ }^{[1-4]}$. We previously advanced a metabolic hypothesis that seeks to explain the relationship between weight loss and improved cardiac and metabolic function ${ }^{[5]}$. While some of these benefits are observed within the first few months, the alteration of the gastrointestinal anatomy and physiology is not without consequence and patients are predisposed to nutritional and metabolic complications ${ }^{[6,7]}$. Another consequence of rapid weight loss appears to be the Published by Sciedu Press 
impact on liver function. While nonalcoholic steatohepatitis in obese patients improves with weight loss surgery, the rate and degree of weight loss may predispose patients to the development of portal inflammation and fibrosis ${ }^{[8]}$.

The positive and negative outcomes of weight loss surgery are secondary to multifactorial and interrelated processes; the rate and degree at which weight loss occurs likely plays a role in the evolution of both. In this report we highlight the beneficial and negative consequences of bariatric surgery on the heart and liver, respectively.

\section{Case report}

\subsection{Patient A}

Patient A was a 58-year-old Caucasian woman with clinically severe obesity who underwent laparoscopic gastric banding (LGB). She was part of a larger cohort of patients followed by us for two years after surgery ${ }^{[9,10]}$, and the only patient among the 42 patients to exhibit severe left ventricular systolic dysfunction. At surgery she weighed $128.1 \mathrm{~kg}$ with a BMI of $48.8 \mathrm{~kg} / \mathrm{m}^{2}$ and $53.2 \%$ fat mass (FM) (see Figure 1A, top panel). Aside from obstructive sleep apnea, treated with continuous positive airway pressure (CPAP), she suffered from hypertension and non-ischemic systolic and diastolic heart failure. For treatment of hypertension, the patient received valsartan $(160 \mathrm{mg} / \mathrm{d})$ and hydrocholorthiazide $(25 \mathrm{mg} / \mathrm{d})$. Echocardiography demonstrated left ventricular hypertrophy (left ventricular mass, LVM $=108 \mathrm{~g} / \mathrm{m}^{2.7}$, upper limit of normal: $47 \mathrm{~g} / \mathrm{m}^{2.7}$ ) and a reduced left ventricular ejection fraction (LVEF=29\%). There was evidence of pre-diabetes (fasting serum glucose $=114 \mathrm{mg} / \mathrm{dL}$ ), but fasting insulin levels and HOMA-IR (homeostasis model of insulin resistance) values were normal. The hemoglobin A1c was $6.4 \%$ and fasting triglyceride levels were $240 \mathrm{mg} / \mathrm{dL}$. There was no evidence of liver dysfunction. She did not use tobacco or drink alcohol.

In the postoperative period weight loss was most pronounced in the first three months (Figure 1A, top panel). At three months, fasting serum glucose levels were normal $(96 \mathrm{mg} / \mathrm{dL})$, and the patient no longer required either antihypertensive medications or CPAP. Nine months after surgery the rate of weight loss had slowed, and her systolic blood pressure required reinstitution of treatment with lisinopril $(10 \mathrm{mg} / \mathrm{d})$ and hydrocholorthiazide $(25 \mathrm{mg} / \mathrm{d})$. However, in spite of a subtle return of the comorbidity there was a dramatic effect on cardiac structure and function. After an initial decline to $23 \%$ at three months the LVEF improved progressively (see Figure 1A, bottom panels). Over the same time there was a nearly linear decline in LVM. At two years both LVEF and LVM were normal (see Figure 1A, bottom panels), although the patient was still clinically obese (BMI $36.5 \mathrm{~kg} / \mathrm{m}^{2}, 47 \% \mathrm{FM}$ ). She returned to full time work within two months. While we have previously observed improved diastolic function, and a progressive decrease in LVM in obese patients following weight loss surgery ${ }^{[9-11]}$, in this patient there was a dramatic improvement in left ventricular systolic function as well.

\subsection{Patient B}

Patient B was a 27-year-old Hispanic-American man with normal cardiac function who underwent Roux-en-Y gastric bypass surgery (RYGB) for morbid obesity refractory to medically-supervised weight loss regimens. Approximately one year after the surgery he was referred to our institution for evaluation for liver transplantation with the diagnosis of cryptogenic cirrhosis. We retrospectively reviewed the patient's record and report on data gathered before and after his referral.

At the time of surgery, the patient weighed $262.6 \mathrm{Kg}$ (BMI of $81.0 \mathrm{~kg} / \mathrm{m}^{2}$ ) and suffered from hypertension, but no metabolic imbalance. He had no history of diabetes, cardiovascular disease, or liver disease. He was not a smoker and did not drink alcohol. Fasting serum glucose levels were $96 \mathrm{mg} / \mathrm{dL}$ and triglyceride levels were $140 \mathrm{mg} / \mathrm{dL}$. A hepatic function panel was normal. An electrocardiogram was normal. After surgery the weight loss was very rapid (see Figure 1B, top panel). In addition, the patient experienced persistent diarrhea, nausea, vomiting, and anorexia. In the first postoperative year, the patient was evaluated at an outside hospital for worsening of these symptoms, for abdominal distension, and for muscle wasting. He was found to have to be cachectic with large amount of ascities. Pre- and post-operative plasma levels 
of total protein and albumin are depicted in Figure 1B, bottom panels. The decline in both blood components reflects impaired biosynthetic function of the liver. Fourteen months after surgery, the patient was admitted for transplant evaluation. On physical exam, he appeared cachectic and weighed $90.9 \mathrm{~kg}\left(\mathrm{BMI} 28.1 \mathrm{~kg} / \mathrm{m}^{2}\right)$ with a distended and tender abdomen showing shifting dullness secondary to ascities. He exhibited asterixis, spider nevi, temporal wasting, atrophic upper limbs, and $2+$ pitting edema in the lower extremities. A paracentesis was performed and $5 \mathrm{~L}$ of a transudative fluid were drained. Abdominal and pelvic computed tomography scans indicated portal hypertension, including a minimally prominent portal vein, anasarca, ascities, and splenomegaly. Fasting serum glucose level was normal (97 mg/dL). Abnormal laboratory findings included: $\mathrm{Na}^{+} 125.0 \mathrm{mmol} / \mathrm{L}$, total protein $5.1 \mathrm{~g} / \mathrm{dL}$, albumin $1.8 \mathrm{~g} / \mathrm{dL}$, alkaline phosphatase 146/1U/L, INR 1.5, Hb11.5 g/dL, total serum iron $28 \mu \mathrm{g} / \mathrm{dL}$, ferritin $1173 \mathrm{ng} / \mathrm{mL}$, iron saturation $35 \%$, antismooth muscle antibody titers were 1:120. Workup for hepatitis and HIV were negative; esophagogastroduodenoscopy revealed a small gastric pouch, but no stenosis, obstruction, or esophageal varicies. A transjugular liver biopsy revealed increased iron deposition and cirrhosis of the liver. No focal hepatic lesions were identified. Workups for viral or autoimmune hepatitis, for Wilson's disease and for hemochormoatosis were negative. The diagnosis of cryptogenic cirrhosis stage IV was made with a Model of Endstage Liver Disease score of 13; the patient was placed on the transplant list. The patient's cardiac workup included an echocardiogram with normal left ventricular systolic and diastolic function (LVEF 60\%-65\%). Prophylactic treatment of spontaneous bacterial peritonitis was instituted and the patient was eventually placed on total parenteral nutrition. The patient continued to lose weight with worsening cachexia and ascities requiring multiple subsequent paracenteses. Yet in spite of a dramatic course with multiple subsequent hospital admissions and BMI reaching a nadir of $23.8 \mathrm{~kg} / \mathrm{m}^{2} 18$ months after surgery (see Figure 1B, top panel), the patient was managed conservatively, as described. The degree of weight loss stabilized and liver function was noted to gradually improve with time. He has since made a protracted recovery and is no longer on the transplant list; he is back to work at 28 months after surgery.
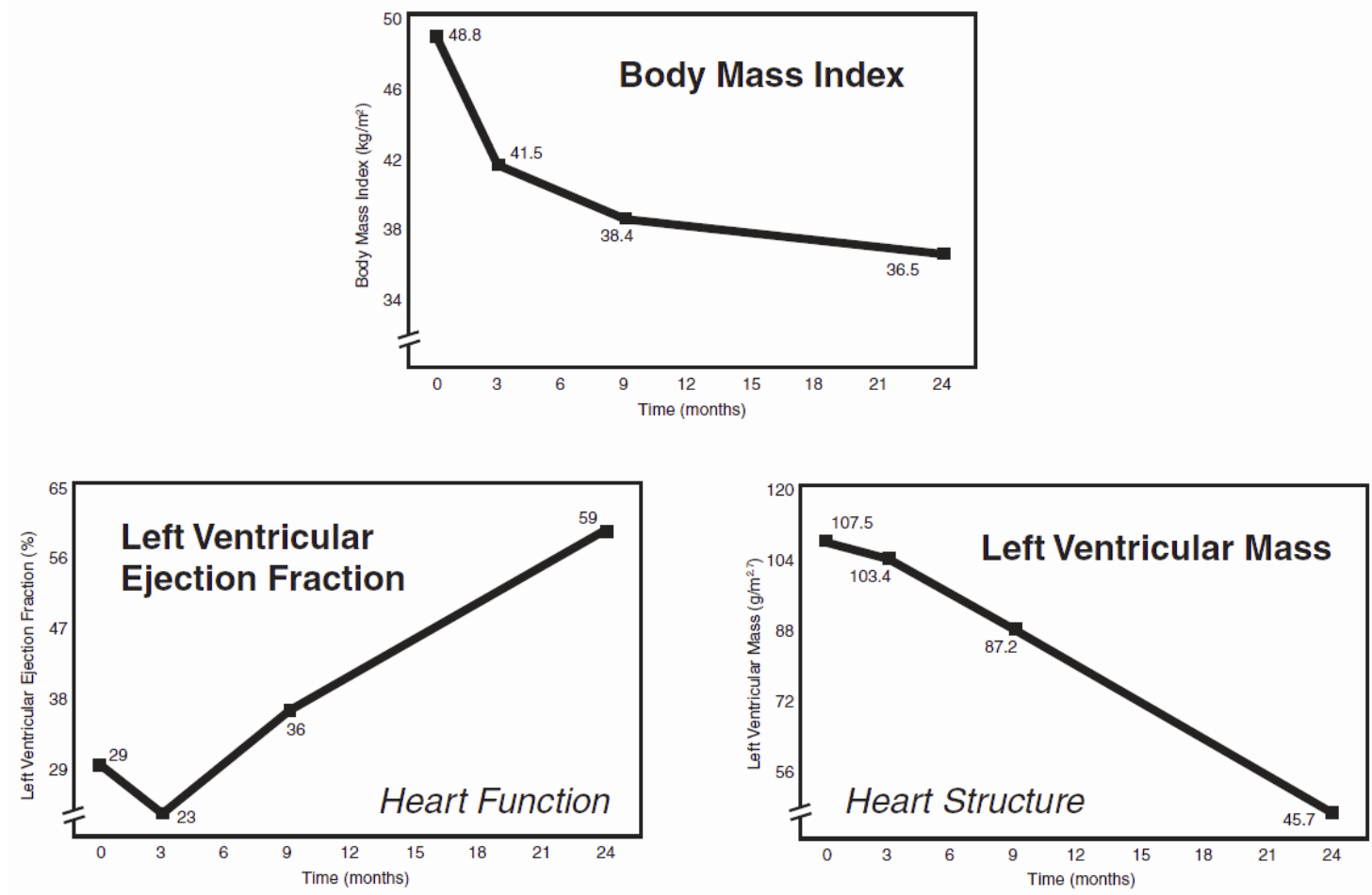

Figure 1A. Contrasting outcomes of weight loss surgery showing improvements in impaired cardiac function (Patient A) and development of impaired liver function (Patient B). Panels A depict serial measurements of BMI, LVEF and LVM for Patient A. 

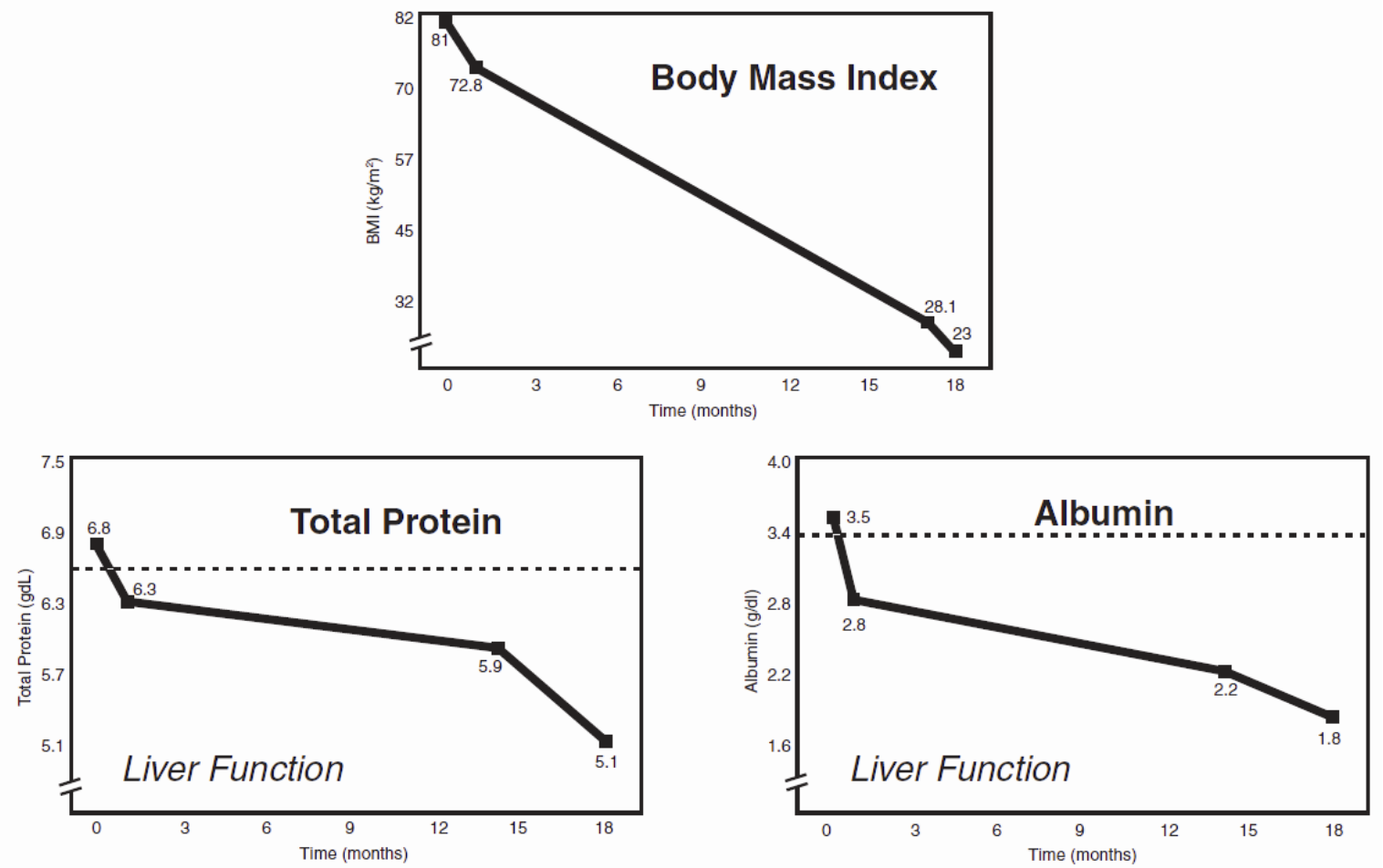

Figure 1B. Contrasting outcomes of weight loss surgery showing improvements in impaired cardiac function (Patient A) and development of impaired liver function (Patient B). Panels B depict serial measurements of BMI, total protein and albumin for Patient B. The lower limits of normal are shown as broken lines. See text for more detail.

\section{Discussion}

The basic and clinical science underpinnings of bariatric surgery procedures are still evolving. Here we describe the contrasting outcomes of two severely obese patients after weight loss surgery in order to draw attention to the potential for reverse remodeling of the failing heart on the one hand, and the potential for pathologic remodeling of the liver on the other hand. Before surgery Patient A was considered a relatively high risk patient with metabolic syndrome and heart failure prior to surgery, yet the patient responded overall better to weight loss surgery than Patient B, who was metabolically healthier and considered a relatively lower risk patient. The lack of concomitant cardiac complications in Patient B suggests that the heart may remain resolute in the face of metabolic disorder induced by rapid weight loss after surgery. The question is: What accounts for the difference in the outcomes; does the patient's metabolic profile and comorbidities prior to surgery contribute to the outcome of weight loss surgery? What role does the rate and degree of weight loss play in the evolution of benefits and complications after bariatric surgery?

For Patient A, bariatric surgery was a life-saving procedure that led to substantial weight loss and simultaneous reversal of the patient's failing heart and the metabolic derangements and comorbidities. Of interest was the reversal of heart dysfunction beyond the improvement in weight and correction of metabolic imbalance, without evidence of liver dysfunction. Weight loss surgery appears to break the vicious cycle of pre-diabetes, hypertension, and increased systemic levels of catecholamines. These factors are associated with the metabolic syndrome and have been implicated in the development of left ventricular hypertrophy and failure in the obese ${ }^{[12-16]}$. In a series of papers ${ }^{[9,10,17,18]}$ we have been able to corroborate the positive effect of weight loss surgery on the metabolic profile, muscle metabolism, and cardiac structure and function. We demonstrated the reversal of lipid accumulation in muscle ${ }^{[9]}$ and evidence of progressive cardiac remodeling for at least two years after surgery while patients remained clinically obese ${ }^{[10]}$. Also, despite the apparent 
complications of weight loss surgery observed in Patient B, the lack of concomitant cardiac complications emphasizes the beneficial effects of weight loss surgery on the heart. We postulated that bariatric surgery improves cardiac function by alleviating the metabolic and mechanical stressors of obesity on the heart ${ }^{[5]}$. Yet, even though Patient B maintained normal cardiac function after surgery, the development of cryptogenic cirrhosis of the liver calls attention to yet another potential grave consequence of weight loss surgery. We are not the first to report hepatic complications with weight loss surgery. The development of NASH has been reported in patients who underwent jejunoileal gastric bypass surgery or sudden rapid weight loss, but it has not been specifically associated with the modern techniques of weight loss surgery ${ }^{[19,20]}$. Vice versa, several recent studies have reported improvement of NAFLD in clinically severe obese patients after weight loss surgery ${ }^{[21,22]}$. The reason for the development of liver cirrhosis and muscle wasting in Patient $\mathrm{B}$ remains unclear. The rate and degree at which weight is lost along with the acuity in the shift of in-body composition in the early months postoperatively may play a role. In a prospective study of morbidly obese patients undergoing caloric restriction with diet and gastroplasty, Andersen et al. demonstrated a higher risk of portal inflammation and fibrosis in patients with fast weight reduction ${ }^{[8]}$. Roux-en-Y gastric bypass is associated with more pronounced and rapid weight loss, dumping syndrome, nutritional and metabolic complications, and a rapid shift in body composition that may altogether account for the liver complication observed with Patient B. It is tempting to further speculate that RYBG surgery results in the generation of some form of hormonal signals which have yet to be identified in this case.

\section{Conclusion}

The divergent response to non-pharmacological weight loss suggests that obesity is not a homogenous entity. After surgery the patient with previous heart failure and the metabolical syndrome lost weight, reversed the heart failure, and reversed the metabolic syndrome, while the previously metabolically healthy patient rapidly lost weight and developed hepatic cirrhosis. We speculate that weight loss surgery can be cardioprotective in patients exhibiting features of the metabolic syndrome and insulin resistance, but may be a metabolic risk for the liver. Whether the metabolic profile or comorbidities prior to surgery contribute to the outcomes of weight loss surgery remains to be determined. Nonetheless, we hope that our experiences may help in the evaluation of patients considered for weight loss surgery and consideration of the possibility liver complications postoperatively.

\section{Acknowledgements}

Part of the work presented was supported by a grant from the NHLBI (R01HL73162) to H.T. The authors thank surgeons at The University of Texas Center for Bariatric Surgery for permission to report on their patients, Drs. David Aguilar and Susan Liang for echocardiographic analyses, and Mrs. Roxy Tate for expert editorial assistance.

\section{References}

[1] Sjostrom L, Lindroos AK, Peltonen M, Torgerson J, Bouchard C, Carlsson B, et al. Lifestyle, diabetes, and cardiovascular risk factors 10 years after bariatric surgery. N Engl J Med. 2004; 351: 2683-93. PMid:15616203 http://dx.doi.org/10.1056/NEJMoa035622

[2] Sjostrom L, Narbro K, Sjostrom CD, Karason K, Larsson B, Wedel H, et al. Effects of bariatric surgery on mortality in Swedish obese subjects. N Engl J Med. 2007; 357: 741-752. PMid:17715408 http://dx.doi.org/10.1056/NEJMoa066254

[3] Adams TD, Gress RE, Smith SC, Halverson RC, Simper SC, Rosamond WD, et al. Long-term mortality after gastric bypass surgery. N Engl J Med. 2007; 357: 753-761. PMid:17715409 http://dx.doi.org/10.1056/NEJMoa066603

[4] Bray GA. The missing link - lose weight, live longer. N Engl J Med. 2007; 357: 818-820. PMid:17715415 http://dx.doi.org/10.1056/NEJMe078135

[5] Algahim MF, Sen S, Taegtmeyer H. Bariatric surgery to unload the stressed heart: A metabolic hypothesis. Am J Physiol Heart Circ Physiol. 2012; 302: H1539-1545. PMid:22307676 http://dx.doi.org/10.1152/ajpheart.00626.2011

[6] Lynch RJ, Eisenberg D, Bell RL. Metabolic consequences of bariatric surgery. Journal of clinical gastroenterology. 2006; 40: 659-668. PMid:16940875 http://dx.doi.org/10.1097/00004836-200609000-00001 
[7] Xanthakos SA, Inge TH. Nutritional consequences of bariatric surgery. Curr Opin Clin Nutr Metab Care. 2006; 9: 489-496. PMid:16778582 http://dx.doi.org/10.1097/01.mco.0000232913.07355.cf

[8] Andersen T, Gluud C, Franzmann MB, Christoffersen P. Hepatic effects of dietary weight loss in morbidly obese subjects. Journal of hepatology. 1991; 12: 224-29. http://dx.doi.org/10.1016/0168-8278(91)90942-5

[9] Leichman JG, Wilson EB, Scarborough T, Aguilar D, Miller CC, III, Yu S, et al. Dramatic reversal of derangements in muscle metabolism and diastolic left ventricular function after bariatric surgery. Am J Med. 2008; 121: 966-73. PMid:18954843 http://dx.doi.org/10.1016/j.amjmed.2008.06.033

[10] Algahim MF, Lux TR, Leichman JG, Boyer AF, Miller CC, III, Laing ST, et al. Progressive regression of left ventricular hypertrophy two years after bariatric surgery: An unexpected dissociation with the body mass index. Am J Med. 2010; 123: 549-55. PMid:20569762 http://dx.doi.org/10.1016/j.amjmed.2009.11.020

[11] Leichman JG, Aguilar D, King TM, Mehta S, Majka C, Scarborough T, et al. Improvements in systemic metabolism, anthropometrics, and left ventricular geometry 3 months after bariatric surgery. Surg Obes Relat Dis. 2006; 2: 592-99. PMid:17138229 http://dx.doi.org/10.1016/j.soard.2006.09.005

[12] Reaven GM. Pathophysiology of insulin resistance in human disease. Physiol Rev. 1995; 75: 473-86. PMid:7624391

[13] Reaven GM, Lithell H, Landsberg L. Hypertension and associated metabolic abnormalities--the role of insulin resistance and the sympathoadrenal system. N Engl J Med. 1996; 334: 374-81. PMid:8538710 http://dx.doi.org/10.1056/NEJM199602083340607

[14] Szczepaniak LS, Dobbins RL, Metzger GJ, Sartoni-D'Ambrosia G, Arbique D, Vongpatanasin W, et al. Myocardial triglycerides and systolic function in humans: In vivo evaluation by localized proton spectroscopy and cardiac imaging. Magn Reson Med. 2003; 49: 417-23. PMid:12594743 http://dx.doi.org/10.1002/mrm.10372

[15] Sharma S, Adrogue JV, Golfman L, Uray I, Lemm J, Youker K, et al. Intramyocardial lipid accumulation in the failing human heart resembles the lipotoxic rat heart. Faseb J. 2004; 18: 1692-1700. PMid:15522914 http://dx.doi.org/10.1096/fj.04-2263com

[16] McGavock JM, Victor RG, Unger RH, Szczepaniak LS. Adiposity of the heart, revisited. Ann Intern Med. 2006 ; 144: $517-524$. PMid:16585666 http://dx.doi.org/10.7326/0003-4819-144-7-200604040-00011

[17] Leichman JG, Aguilar D, King TM, Vlada A, Reyes M, Taegtmeyer H. Association of plasma free fatty acids and left ventricular diastolic function in patients with clinically severe obesity. Am J Clin Nutr. 2006; 84: 336-41. PMid:16895880

[18] Trakhtenbroit MA, Leichman JG, Algahim MF, Miller CC, 3rd, Moody FG, Lux TR, Taegtmeyer H. Body weight, insulin resistance, and serum adipokine levels 2 years after 2 types of bariatric surgery. Am J Med. 2009; 122: 435-442. PMid:19375553 http://dx.doi.org/10.1016/j.amjmed.2008.10.035

[19] Chitturi S, Farrell GC. Etiopathogenesis of nonalcoholic steatohepatitis. Semin Liver Dis. 2001; 21: 27-41. http://dx.doi.org/10.1055/s-2001-12927

[20] McClain CJ, Mokshagundam SP, Barve SS, Song Z, Hill DB, Chen T, et al. Mechanisms of non-alcoholic steatohepatitis. Alcohol. 2004; 34: 67-79. PMid:15670668 http://dx.doi.org/10.1016/j.alcohol.2004.07.007

[21] Mattar SG, Velcu LM, Rabinovitz M, Demetris AJ, Krasinskas AM, Barinas-Mitchell E, et al. Surgically-induced weight loss significantly improves nonalcoholic fatty liver disease and the metabolic syndrome. Ann Surg. 2005; 242: 610-617; discussion 618-20. PMid:16192822

[22] Promrat K, Kleiner DE, Niemeier HM, Jackvony E, Kearns M, Wands JR, et al. Randomized controlled trial testing the effects of weight loss on nonalcoholic steatohepatitis. Hepatology. 2010; 51: 121-29. PMid:19827166 http://dx.doi.org/10.1002/hep.23276 